\title{
Comparison of Dynamic Balance under Dual and Simple Task Conditions in Children with Attention Deficit Hyperactivity Disorder
}

\author{
Ying-Yi Chen $^{1)}$, Chia-Hsin $\mathrm{CHEN}^{2)}$, Chin-Chung Wang ${ }^{2)}$, \\ Lih-Jiun LiaW ${ }^{3)}$, Lan-Yuen Guo ${ }^{1,4)}$, Wen-Lan Wu',4) \\ 1) Department of Sports Medicine, Kaohsiung Medical University: 100 Shih-Chuan 1st Road, \\ Kaohsiung, 80708, Taiwan. TEL: +886 7-3121101-2646, FAX: +886 7-3138359,Email: wenlanwu@, \\ kmu.edu.tw \\ 2) Department of Physical and Rehabilitation Medicine, Kaohsiung Medical University Hospital \\ 3) Department of Physical Therapy, Kaohsiung Medical University \\ 4) Medical Device Innovation Center, National Cheng Kung University
}

\begin{abstract}
Purpose] The purpose of this study was to make a comparison of dynamic balance ability between dual and simple task conditions. [Subjects and Methods] Nine children with attention deficit hyperactivity disorder $(9.00$ \pm 2.12 years) and 10 healthy children $(9.67 \pm 2.75$ years $)$ were recruited. Each group was asked to do an obstacle crossing alone and the obstacle crossing combined with a stimulus response task. The Qualisys motion capture system was used to capture full-body motion. The parameters measured included crossing speed, step width, and reaction time. [Results] Children with attention deficit hyperactivity disorder had greater problems than controls in performing the primary balance task while concurrently completing the auditory reaction time task and showed greater variability in step width and a longer reaction time. The balance scores assessed using the Movement Assessment Battery for Children test were significantly worse in the attention deficit hyperactivity disorder group and were significantly correlated to the crossing reaction time and variance of crossing speeds.[Conclusion] The attention deficit hyperactivity disorder group preferred to complete the obstacle crossings before responding to the stimulus. This resulted in a longer reaction time for the secondary task and also changed the gait strategy.

Key words: Attention deficit hyperactivity disorder (ADHD), Obstacles crossing
\end{abstract}

(This article was submitted Jan. 12, 2012, and was accepted Feb. 12, 2012)

\section{INTRODUCTION}

Attention deficit hyperactivity disorder (ADHD) is a kind of neurobehavioral developmental disorder. ADHD affects 3 to $5 \%$ of school-age children in the U.S $\$$. Children who are diagnosed with ADHD often experience significant sensory motor problems that make typical school activities a challenge. These children are more prone to injuries, such as falls, being struck by an object, poor performance in physical education classes and fractures. In the long run, these impaired performances may influence their school activities and lifestyle. This, in turn, draws parents' attention to the underlying problems.

Previous studies support the notion that ADHD may contribute to fine motor difficulties; however, children with ADHD were found to have poorer performance not only in fine motor skills, but also greater difficulty in gross motor skills. Most children with ADHD have poor balance f $_{\text {f }}$ and motor coordination dysfunction $2,4,5$. In the evaluation of standing stability of children with ADHD, it was shown that they have greater sway velocity than controls under various conditions ${ }^{6-8}$. ADHD participants also showed an increased number of falls, especially when standing on a sway-refer- enced platform 9 . Moreover, previous studies have shown that medical treatments, such as Methylphenidatep), can improve poor balance control $10-12$.

In addition to motor problems, neuro-pathological changes in the brains of ADHD children may lead to deterioration in dual-task performance. Previous studies have demonstrated that enhancement of attention abilities for children with ADHD may improve their gait rhythm 12. This result verifies the relationship between attention and the control of posture and gait. Moreover, in conditions of high-level controlled processing, requiring the allocation of attentional capacity, some researchers have used computerized motor control tasks to investigate children at risk of ADHD ${ }^{13}$. Their findings show that children with ADHD are less accurate and have less stable performance than healthy controls.

Also, the attentional demands of balance control vary depending on the complexity of the task being performed 4 . Indeed, crossing obstacles requires more complex motor skills than walking. Obstacle crossing during walking is a continuous and repetitive movement. People have to balance their moving body and adapt a motor program to meet the needs in different environments 15 . Obstacle crossing during 
walking requires precise control of the trailing foot to support body balance ${ }^{16,17}$. Postural deficits become more apparent during obstacle crossing by either widening the step or increasing the time spent in double limb support For ADHD children, neuro-pathological changes in the brain may lead to a decrease in the performance of obstacle crossing, but the degree of this impairment effect is unclear. Therefore, the purpose of this study was to investigate healthy children's motor skills during obstacle-crossing under attention demanding dual-task conditions, and compare them with those of children with ADHD.

\section{SUBJECTS AND METHODS}

Eight boys and one girl with a mean age of $9.00 \pm 2.12$ years, diagnosed with ADHD, were recruited from the Kaohsiung Medical Hospital and a local hospital. The participants were diagnosed by medical centers or local rehabilitation clinics as having ADHD without other syndromes, such as Autism. Three ADHD subjects were treated with medicines for symptom control. However, all these subjects took drug holidays during the study. Ten age-matched children ( 7 boys and 3 girls, mean age $9.67 \pm 2.75$ years), without neuromuscular symptoms, were recruited from local schools as the control group. This study was approved by the institutional review board of Kaohsiung Medical University Hospital. Informed consent was obtained from the children's parents prior to their involvement in the study.

Ten obstacles, $(80 \mathrm{~cm} * 8 \mathrm{~cm})$, made from corrugated plastic and paper, were placed separately on two vertical plastic stands, set on the path. The height of the vertical stands was set at approximately $30 \%$ of the leg length of the subjects (from the anterior superior iliac spine to the lateral malleolus while standing). The distance between the two obstacles was set at $20 \%$ of the leg length of each subject. A six-camera motion capture system (Qualisys Motion Capture Systems, Qualisys AB, Sweden) was set up along the path to measure the three-dimensional positions of reflective markers attached to the subject, using a sampling frequency of $100 \mathrm{~Hz}$. A sound operating system $\left(\right.$ STIM $^{2}$ Acquisition Software, Compumedics Neuroscan, USA) was used to provide a stimulus tone to the subject. During reaction time (RT) tests, a self-assembled radio telemetry handheld trigger was used to signal a response. The stimulus tone and reaction signals were recorded simultaneously on a notebook computer. Furthermore, all participants were asked to finish the M-ABC test (Movement Assessment Battery for Children), which has proven validity and reliability $19-21$.

Lightweight reflective markers were attached to the skin of the subjects over the following bony landmarks: bilaterally over the anterior superior iliac spine (ASIS), the sacrum, and each side of the lateral mid-thigh, the lateral femoral condyle of the thigh, the lateral malleolus, the calcaneus, the fifth metatarsal head, the acromion, the lateral epicondyle of the humerus, and the radial and the ulnar styloid processes. The participants were familiarized with the signal tones $(2 \mathrm{kHz}$ tones) before the formal test and were instructed to walk at their self-selected fastest speed and press the button with the dominant hand as soon as possible upon hearing the tone signal. The stimulus signal was programmed to occur once within the middle 5 steps for each trial, and to be sustained for $100 \mathrm{msec}$.

All subjects were required to complete the obstacle crossing. There were two different test conditions: a single task (obstacle crossing alone) and a dual-task (obstacle crossing plus hand button pressing tasks).

In the single task, each subject was asked to stand with a symmetric stance in front of the first obstacle at the starting point. Subjects were then asked to perform barefooted obstacle crossing from one end of the path to the other end at a fast pace, and with no rest in each trial. In total, each subject was asked to perform 5 barefoot trials and the middle 5 steps in each trial were averaged to calculate the whole body gait parameter data.

In the dual-task, subjects had to perform two tasks simultaneously: the obstacle crossing task and the hand button pressing task. Each participant was instructed to press the button, using their preferred hand, when he/she heard the tone signal. Each obstacle crossing trial lasted approximately $10 \mathrm{~s}$. The subject then returned to the starting position and waited several seconds for the next trial to begin. Between trials, the subjects were allowed to rest or sit, as they preferred, but fatigue was never an issue. In total, each subject performed 5 trials for this test condition and the middle 5 steps of each trial were averaged to calculate the whole body gait parameter data.

In addition, the Movement Assessment Battery for Children test (M-ABC) was used to assess the general motor performance of each participant. This test is designed for children between 4 and 12 years of age and consists of 32 items, subdivided into 4 age bands. Each age band includes 8 individual test items, measuring movement skills in three categories: manual dexterity skills, ball skills and balance skills. Each item is rated on a 6-point rating scale, where 5 corresponds to the weakest performance and 0 corresponds to the best performance. The subsclae scores of the M-ABC test for each child were recorded.

The signals from the stimulus tone and the radio telemetry receiver were collected at $1000 \mathrm{~Hz}$. Reaction time (RT) was calculated as the time difference between the stimulus tone signal onset and the response signal onset.

Qualisys Track Manager Software (Qualisys Motion capture Systems, Qualisys AB, Sweden) was used to track the markers in space for $10 \mathrm{~s}$ at $100 \mathrm{~Hz}$. All marker data were low-pass filtered using a Butterworth filter with a cut-off frequency of $6 \mathrm{~Hz}$, and interpolated with a maximum gap fill of 10 frames using a 3rd degree polynomial. An 11-segment, full-body model (forearms, upper arms, head + trunk, thighs, shanks, feet) was constructed in Visual3D, and the first time derivates of three-dimensional position data of COM (centre of mass) (crossing speed, $\mathrm{cm} / \mathrm{s}$ ) were calculated using Visual3D. The step width was defined as the distance between the rear end of the right and left heel centerlines along the mediolateral axis, and the step width was normalized to the distance between the bilateral ASIS (anterior superior iliac spines). Furthermore, the mean (MCS) and variance (VCS) of crossing speeds and the mean (MSW) and variance (VSW) of normalized step width were 
computed to describe the typical value and its variability. High values of MSW represent greater step width in crossing obstacles and high values of VSW represent inconsistent performance. High values of MCS represent faster speeds, and high values of VCS indicate inconsistency in speed during obstacle crossing.

Descriptive statistics were used in this study to describe the mean and variability of crossing speed and normalized step width during the obstacle crossing tasks. The subscale scores of the Movement $\mathrm{ABC}$ tests and reaction time (RT) of tone discrimination were compared between the two groups using Student's t-test. The statistical significance of crossing speed and normalized step width differences were analysed using a mixed design employing analysis of variance with repeated measures of task (two conditions) and independent measures of group (groups). Logarithmic transformations were conducted on all dependent variables to reduce the variability and general positive skew of the data. Pearson's correlation coefficient was calculated to examine the relationships between the following variables: balance score, crossing reaction time and gait parameters. All analyses were carried out using SPSS version 17 for Windows (SPSS Inc. Chicago, USA). Results were considered statistically significant when the p-value was less than 0.05 .

\section{RESULTS}

In the subscale of $\mathrm{M}-\mathrm{ABC}$, higher scores indicate poorer skills. In this study, we found that the balance skill scores $(\mathrm{p}<0.01$, Table 1$)$ and ball skills $(\mathrm{p}<0.01$, Table 1$)$ were significantly higher in the ADHD group. Table 1 also showed that the crossing RT was shorter for controls than for that of the ADHD group subjects $(\mathrm{p}<0.05$, Table 1$)$.

Table 2 presents the descriptive statistics of four gait parameters in each of the two task conditions: single task (obstacle crossing alone, ST) and dual task (obstacle crossing plus hand button pressing tasks, DT) across groups. The four gait parameters were MCS, VCS, MSW, and VSW.

The results of the normalized step widths in Table 2 show that there were significant main effects of group $(p<0.05)$ on VSW and a significant interaction between task effect and
Table 1. Subscales of Movement $A B C$ measures and crossing reaction times (RT, sec) of the crossing stride ofo the ADHD and control groups (mean value with standard deviation in parenthese)

\begin{tabular}{llc}
\hline & ADHD $(\mathrm{n}=9)$ & Control $(\mathrm{n}=10)$ \\
\hline Balance skill & $4.72(3.20)^{* *}$ & $0.72(0.63)$ \\
Ball skill & $5.69(2.76)^{* *}$ & $1.10(1.96)$ \\
Manual dexterity & $8.29(3.95)$ & $5.83(3.96)$ \\
Crossing RT (ms) & $0.55(0.11) *$ & $0.45(0.09)$ \\
\hline
\end{tabular}

$*$ denotes $\mathrm{p}<0.05, * *$ denotes $\mathrm{p}<0.01$ compared across groups.

group effect $(\mathrm{p}<0.05)$ on MSW. In the DT condition, ADHD participants increased their step width while the controlsubjects decreased their step width (Table 2). No significant differences were found between the group effect and the task effect on MCS or VCS (Table 2).

Pearson's correlation coefficients were calculated to reveal the relationships among the scores of balance, crossing RT, and gait parameters. In the ADHD group, the balance score of $\mathrm{M}-\mathrm{ABC}$ showed a significant correlation with crossing RT ( $\mathrm{p}<0.05, \mathrm{r}=0.68$, Table 3$)$, but not in the control group (Table 4). In contrast, in the control group, crossing RT showed a significant negative correlation with VCS $(p<0.05, r=-0.69$, Table 4$)$. With regard to the gait parameters, MCS and MSW in ST and DT had significant positive correlations in both groups (Tables 3 and 4). In the ADHD group, a positive correlation was found between the balance score and VCS in ST $(\mathrm{p}<0.05, \mathrm{r}=0.70$, Table 3$)$. However, in the control group, a significant correlation was found between VSW and MSW in the single task condition $(\mathrm{p}<0.05, \mathrm{r}=0.76$, Table 4$)$.

\section{DISCUSSION}

Previous research has shown that children with ADHD experience significantly greater difficulty with balance skills 822 and gross motor skills than healthy children. It has also been indicated that children with ADHD have behavioral inhibition deficits, especially for difficult tasks ${ }^{23}$.

Table 2. Gait parameters of obstacle crossing. The value of the mean crossing speed, variability of the crossing speed, mean step width, and variability of the step width of the crossing stride are shown (mean value with standard deviation in parentheses). N-Step width: step width was normalized to the distance between ASIS. (ST-single task; DT-dual task)

\begin{tabular}{lllll}
\hline \multicolumn{3}{c}{ ADHD $(\mathrm{n}=9)$} & \multicolumn{3}{l}{ Control $(\mathrm{n}=10)$} \\
\hline $\begin{array}{l}\text { Gait parameter } \\
\text { crossing speed }(\mathrm{cm} / \mathrm{s})\end{array}$ & ST & DT & ST & DT \\
$\quad$ mean & $66.13(23.67)$ & $67.73(28.87)$ & $57.86(12.64)$ & $56.13(10.93)$ \\
$\quad$ variability & $61.07(23.03)$ & $75.87(39.09)$ & $61.00(18.78)$ & $58.54(16.45)$ \\
$\begin{array}{l}\text { N-step width } \\
\text { mean }\end{array}$ & & & & \\
$\quad$ variability & $0.57(0.22)$ & $0.65(0.16)$ & $0.53(0.26)$ & $0.46(0.19)$ \\
\hline
\end{tabular}

\#1 denotes a significant interaction between group effect (ADHD vs. Control) and task effect (ST vs. DT) with a $\mathrm{p}$ value $<0.05$. ${ }^{22}$ denotes a significant group main effect (ADHD vs. Control) on the variability of N-step width with a $\mathrm{p}$ value $<0.05$ 
Table 3. Pearson correlation coefficients between balance score, crossing RT, and gait parameters for the ADHD group. MCS-mean crossing speed; VCS-variability of crossing speed; MSW-mean N-step width; VSW-variability of N-step width

\begin{tabular}{|c|c|c|c|c|c|c|c|c|c|c|c|}
\hline \multicolumn{2}{|c|}{$\begin{array}{l}\text { Pearson } \\
\text { correlation }\end{array}$} & $\begin{array}{l}\text { balance } \\
\text { score }\end{array}$ & $\begin{array}{l}\text { crossing } \\
\text { RT }\end{array}$ & $\begin{array}{l}\mathrm{MCS} \\
(\mathrm{ST})\end{array}$ & $\begin{array}{l}\text { MCS } \\
\text { (DT) }\end{array}$ & $\begin{array}{l}\mathrm{VCS} \\
(\mathrm{ST}) \\
\end{array}$ & $\begin{array}{l}\text { VCS } \\
\text { (DT) }\end{array}$ & $\begin{array}{l}\text { MSW } \\
(\mathrm{ST})\end{array}$ & $\begin{array}{l}\text { MSW } \\
\text { (DT) }\end{array}$ & $\begin{array}{l}\text { VSW } \\
(\mathrm{ST}) \\
\end{array}$ & $\begin{array}{l}\text { VSW } \\
\text { (DT) }\end{array}$ \\
\hline \multicolumn{2}{|c|}{ Balance score } & 1 & $.68^{*}$ & -.12 & -.08 & $.70 *$ & .15 & -.52 & -.60 & -.09 & .25 \\
\hline \multicolumn{2}{|c|}{ Crossing RT } & & 1 & & -.42 & & .26 & & -.34 & & .41 \\
\hline \multirow[t]{2}{*}{ MCS } & ST & & & 1 & $.98^{* *}$ & -.20 & -.31 & -.09 & -.25 & .08 & -.08 \\
\hline & DT & & & & 1 & -.17 & -.33 & -.09 & -.25 & .08 & -.11 \\
\hline \multirow[t]{2}{*}{ VCS } & ST & & & & & 1 & .50 & -.11 & -.02 & .13 & .34 \\
\hline & DT & & & & & & 1 & -.16 & .11 & .07 & .24 \\
\hline \multirow[t]{2}{*}{ MSW } & ST & & & & & & & 1 & $.89 * *$ & -.61 & .19 \\
\hline & DT & & & & & & & & 1 & -.488 & .07 \\
\hline \multirow[t]{2}{*}{ VSW } & ST & & & & & & & & & 1 & -.38 \\
\hline & DT & & & & & & & & & & 1 \\
\hline
\end{tabular}

$* * \mathrm{p}<0.01 ; * \mathrm{p}<0.05$

Table 4. Pearson correlation coefficients between balance score, crossing RT, and gait parameters for the control group. MCS-mean crossing speed; VCS-variability of crossing speed; MSW-mean step width; VSW-variability of step width

\begin{tabular}{|c|c|c|c|c|c|c|c|c|c|c|c|}
\hline \multicolumn{2}{|c|}{$\begin{array}{l}\text { Pearson } \\
\text { correlation }\end{array}$} & $\begin{array}{l}\text { balance } \\
\text { score }\end{array}$ & $\begin{array}{l}\text { crossing } \\
\text { RT }\end{array}$ & $\begin{array}{l}\text { MCS } \\
\text { (ST) }\end{array}$ & $\begin{array}{l}\text { MCS } \\
\text { (DT) }\end{array}$ & $\begin{array}{l}\text { VCS } \\
\text { (ST) }\end{array}$ & $\begin{array}{l}\text { VCS } \\
\text { (DT) }\end{array}$ & $\begin{array}{l}\text { MSW } \\
\text { (ST) }\end{array}$ & $\begin{array}{l}\text { MSW } \\
\text { (DT) }\end{array}$ & $\begin{array}{l}\text { VSW } \\
\text { (ST) }\end{array}$ & $\begin{array}{l}\text { VSW } \\
\text { (DT) }\end{array}$ \\
\hline \multicolumn{2}{|c|}{ balance score } & 1 & -.16 & -.25 & -.11 & .20 & .33 & .05 & -.01 & .06 & .27 \\
\hline \multicolumn{2}{|c|}{ crossing RT } & & 1 & & -.39 & & $-.69^{*}$ & & .24 & & -.13 \\
\hline MCS & ST & & & 1 & $.92 * *$ & .43 & .17 & .06 & -.02 & .33 & .15 \\
\hline V & DT & & & & 1 & .62 & .26 & .01 & -.17 & .22 & .12 \\
\hline \multirow[t]{2}{*}{ VCS } & $\mathrm{ST}$ & & & & & 1 & .49 & .53 & .19 & .54 & .12 \\
\hline & DT & & & & & & 1 & -.03 & -.16 & .47 & .63 \\
\hline \multirow[t]{2}{*}{ MSW } & ST & & & & & & & 1 & $.88^{*}$ & $.76^{*}$ & .05 \\
\hline & DT & & & & & & & & 1 & .57 & .27 \\
\hline \multirow[t]{2}{*}{ VSW } & $\mathrm{ST}$ & & & & & & & & & 1 & .28 \\
\hline & DT & & & & & & & & & & 1 \\
\hline
\end{tabular}

$* * \mathrm{p}<0.01 ; * \mathrm{p}<0.05$

In the present study, the two-way interaction of effect was found between group and condition in mean step width (Table 2). Children with ADHD struggled to maintain motor performance while processing the auditory reaction time tasks and this influenced step width. Some studies have also found that people with poor balance skills exhibit a wider base of support to manage body stability during obstacle crossing ${ }^{16-18,25}$. In the condition of DT, ADHD participants increased their step width while control subjects decreased their step width. This suggests that in the dual task, subjects in the ADHD group needed to adjust their step width to overcome the interference between the reaction time task and the obstacle crossing task in order to maintain their frontal plane dynamic stability to avoid stumbling.

Previous research has shown that the speed variability of movement may be related to ADHD symptomatology 2 . In the present study, a positive correlation $(\mathrm{r}=0.70, \mathrm{p}<0.05$, Table 3) was found between the balance score and VCS in ST for the ADHD group, was associated with a inferring that poorer balance is related to more variable gait speed. Moreover, the poor balance score caused the longer crossing RT $(r=0.68, p<0.05$, Table 3$)$ in the ADHD group, and the balance score showed no significant correlations with gait parameters, such as the VCS, in the dual task condition. These results suggest that the poor balance skill of ADHD children affects the crossing RT but not gait parameters in dual task condition; i.e. the ADHD children could keep a consistent gait in the dual task condition but their reaction time was affected by their poor balance skill. In the control group, the crossing RT showed a significant negative correlation with VCS in the dual task condition $(r=-0.69, \mathrm{p}<0.05$, Table 4). We also found that for the normal children, the obstacle crossing performance was affected by the dual task, but the balance score was not associated with crossing RT, or gait parameters, suggesting that their balance was sufficient to meet the low attentional demand presented in this study.

To sum up, obstacle crossing performance was influenced by the processing of a dual task in the ADHD group. The ADHD group preferred to widen their step width in order to support their balance and cross obstacles successfully. Although the task condition did not have a statistically significant effect, VCS under DT $(75.87 \mathrm{~ms})$ was observed to be slightly higher than under ST $(61.07 \mathrm{~ms})$, in the ADHD group. This suggests that poor balance skill of ADHD 
children may interferes with stable locomotion, especially under a DT condition.

In this study, balance skill played an important role in processing the dual task. For children with ADHD, impaired balance skill may influence their obstacle crossing performance. Also, poor balance skills interfered with crossing RT and lead to a change in gait strategy. Further studies should design an attentional focus experiment, balance tasks focus or cognitive tasks focus, to evaluate participants' strategies for processing obstacle crossings.

\section{ACKNOWLEDGEMENT}

This work was supported by the National Science Council, Taiwan (NSC 97-2320-B-037-004-MY3).

\section{REFERENCES}

1) Flapper BC, Houwen S, Schoemaker MM: Fine motor skills and effects of methylphenidate in children with attention-deficit-hyperactivity disorder and developmental coordination disorder. Dev Med Child Neurol, 2006, 48: 165-169. Medline CrossRef

2) Piek JP, Pitcher TM, Hay DA: Motor coordination and kinaesthesis in boys with attention deficit-hyperactivity disorder. Dev Med Child Neurol, 1999, 41: 159-165. Medline CrossRef

3) Raberger T, Wimmer H: On the automaticity/cerebellar deficit hypothesis of dyslexia: balancing and continuous rapid naming in dyslexic and ADHD children. Neuropsychologia, 2003, 41: 1493-1497. [Medline] [CrossRef]

4) Kadesjö B, Gillberg C: Attention deficits and clumsiness in Swedish 7-year-old children. Dev Med Child Neurol, 1998, 40: 796-804. [Medline] CrossRef

5) Stray LL, Stray T, Iversen S, et al.: The Motor Function Neurological Assessment (MFNU) as an indicator of motor function problems in boys with ADHD. Behav Brain Funct, 2009, 5: 22. [Medline [CrossRef

6) Buderath P, Gartner K, Frings M, et al.: Postural and gait performance in children with attention deficit/hyperactivity disorder. Gait Posture, 2009, 29: 249-254. [Medline CrossRef

7) Cheng J, Wang YF: Comparison of postural control between normal and attention deficit hyperactivity disorder boys. Beijing Da Xue Xue Bao, 2007, 39: 531-534. Medline

8) Shum BM, Pang YC: Children with Attention Deficit Hyperactivity Disorder Have Impaired Balance Function: Involvement of Somatosensory Visual, and Vestibular Systems. J Pediatr, 2009, 155: 245-249. Medline [CrossRef

9) Smalley SL, McGough JJ, Moilanen IK, et al.: Prevalence and psychiatric comorbidity of attention-deficit/hyperactivity disorder in an adolescent Finnish population. J Am Acad Child Adolesc Psychiatry, 2007, 46: 15751583. Medline] [CrossRef

10) Feng L, Wang YF, Cao QJ: A pilot study on effect of methylphenidate on balance function of children with attention deficit hyperactivity disorder. Beijing Da Xue Xue Bao, 2007, 39: 304-309. [Medline

11) Jacobi-Polishook $T$, Shorer $Z$, Melzer I: The effect of methylphenidate on postural stability under single and dual task conditions in children with attention deficit hyperactivity disorder - a double blind randomized control trial. J Neurol Sci, 2009, 280: 15-21. [Medline [CrossRef

12) Leitner Y, Barak R, Giladi N, et al.: Gait in attention deficit hyperactivity disorder: effects of methylphenidate and dual tasking. J Neurol, 2007, 254: 1330-1338. Medline CrossRef

13) Kalff AC, de Sonneville LM, Hurks PP, et al.: Low- and high-level controlled processing in executive motor control tasks in 5-6-year-old children at risk of ADHD. J Child Psychol Psychiatry, 2003, 44: 1049-1057. [Medline] [CrossRef

14) Woollacott M, Shumway-Cook A: Attention and the control of posture and gait: a review of an emerging area of research. Gait Posture, 2002, 16: 1-14. [Medline [CrossRef

15) Patla AE, Prentice SD, Robinson C, et al.: Visual control of locomotion: strategies for changing direction and for going over obstacles. J Exp Psychol Hum Percept Perform, 1991, 17: 603-634. Medline CrossRef

16) Chen HL, Lu TW, Wang TM, et al.: Biomechanical strategies for successful obstacle crossing with the trailing limb in older adults with medial compartment knee osteoarthritis. J Biomech, 2008, 41: 753-761. Medline] CrossRef

17) Chou LS, Draganich LF: Stepping over an obstacle increases the motions and moments of the joints of the trailing limb in young adults. J Biomech, 1997, 30: 331-337. Medline CrossRef

18) Galna B, Murphy AT, Morris ME: Obstacle crossing in people with Parkinson's disease: foot clearance and spatiotemporal deficits. Hum Mov Sci, 2010, 29: 843-852. [Medline [CrossRef

19) Henderson SE, Sugden DA: Movement Assessment Battery for Children: Manual. London: The Psychological Corporation, Ltd., 1992.

20) Smits-Engelsman BC, Fiers MJ, Henderson SE, et al.: Interrater reliability of the Movement Assessment Battery for Children. Phys Ther, 2008, 88: 286-294. [Medline CrossRef

21) Van Waelvelde H, De Weerdt W, De Cock P, et al.: Aspects of the validity of the Movement Assessment Battery for Children. Hum Mov Sci, 2004, 23: 49-60. [Medline CrossRef

22) Sims AB, Stack BC: An intraoral neurocranial vertical distractor appliance provides unique treatment for Tourette's syndrome and resolves comorbid neurobehavioral problems of obsessive compulsive disorder. Med Hypotheses, 2010, 75: 179-184. [Medline] [CrossRef]

23) Barkley RA, Murphy KR: Attention Deficit Hyperactivity Disorder: A handbook for diagnosis and treatment (2nd ed). New York: Guilford Press, 1998.

24) Huang HJ, Mercer VS, Thorpe DE: Effects of different concurrent cognitive tasks on temporal-distance gait variables in children. Pediatr Phys Ther, 2003, 15: 105-113. Medline CrossRef

25) Law LS, Webb CY: Gait adaptation of children with cerebral palsy compared with control children when stepping over an obstacle. Dev Med Child Neurol, 2005, 47: 321-328. [Medline] CrossRef

26) Pitcher TM, Piek JP, Barrett NC: Timing and force control in boys with attention deficit hyperactivity disorder: Subtype differences and the effect of comorbid developmental coordination disorder. Hum Mov Sci, 2002, 21: 919-945. Medline [CrossRef 